\title{
Paraplegia
}

\section{Autoregulation of Cerebral Blood Flow in Patients with Orthostatic Hypotension After Spinal Cord Injury}

\author{
F. Gonzalez, PA-C ${ }^{1}$, J. Y. Chang, MS, ${ }^{2}$ K. Banovac, MD, ${ }^{1}$ D. Messina, PT, ${ }^{2}$ \\ A. Martinez-Arizala MD,,$^{23}$ R. E. Kelley \\ ${ }^{1}$ Department of Orthopedics and Rehabilitation, ${ }^{2}$ Department of Neurology, and ${ }^{3}$ The \\ Miami Project, University of Miami School of Medicine, Miami, Florida, USA
}

\section{Summary}

Two groups of patients who developed orthostatic hypotension $(\mathrm{OH})$ after spinal cord injury (SCI) were studied. In the first group all patients (4 females and 6 males) were asymptomatic, whereas in the second group (1 female and 9 males) all had clinical manifestations of hypotension. All but 3 patients were tetraplegic, and these patients were paraplegic above the T6 level. For this study blood pressure (BP), heart rate and cerebral blood flow $(C B F)$ velocity were measured simultaneously on a tilt table at 0,30 , 60, and 80 degrees. Cerebral blood flow in the middle cerebral artery was measured bilaterally utilising the transcranial Doppler technique. In asymptomatic patients the mean baseline (0 degrees) $B P(110 \pm 16 / 70 \pm 77 \mathrm{~mm} \mathrm{Hg}$ systolic/diastolic) was not significantly different from the $B P(106 \pm 16 / 68 \pm 11 \mathrm{~mm} \mathrm{Hg})$ of symptomatic patients. The mean maximal change in $B P$ during tilting in the asymptomatic group $(-23 \pm 10 / 10 \pm 7 \mathrm{~mm} \mathrm{Hg})$ was also not significantly different when compared to the symptomatic group $(-29 \pm 13 / 11 \pm 6 \mathrm{~mm} \mathrm{Hg})$. CBF in the symptomatic group during the hypotensive reaction at 80 degrees was $32.5 \pm 5 \mathrm{~cm} / \mathrm{sec}$, while at the same body position in the asymptomatic group it was $40.9 \pm 8 \mathrm{~cm} / \mathrm{sec}$ (significant at the $p<0.02$ ). In addition, $C B F$ decreased in the symptomatic group at 80 degrees to $55 \cdot 5 \pm 9 \cdot 6 \%$ of baseline, while in the asymptomatic group the fall was $69 \cdot 3 \pm 7 \cdot 2 \%(p<0.001)$. Our data suggests that autoregulation of $C B F$ rather than systemic BP plays a dominant role in the adaptation to $\mathrm{OH}$ in patients with SCI.

Key words: Spinal cord injury; Cerebral blood flow; Orthostatic hypotension.

Orthostatic hypotension $(\mathrm{OH})$ is a frequent complication seen in paralysed patients after spinal cord injury (SCI). The pathogenesis of $\mathrm{OH}$ is complex and involves the cardiovascular, the renal, the neurological and the endocrine systems, all of which are necessary for the regulation of arterial blood pressure (Guttmann et al., 1963; 
Johnson et al., 1971; Corbet et al., 1971; Johnson and Park 1973; Vallbona et al., 1966; Kammelhar et al., 1978; Sommers, 1979; Figoni, 1984). The symptoms associated with acute hypotension significantly interfere with the rehabilitation of patients with SCI. Furthermore, hypotensive manifestations may be present for several months until the patients develop tolerance to the low blood pressure.

It has been found in different tissues that the chronic adaptation to hypotension is a result of slowly developing autoregulation of an optimal tissue blood supply (Stainsby, 1973; Johnson, 1984). Nanda et al. (1974) suggested that autoregulation of cerebral blood flow occurs in patients with SCI and showed that in these patients a significant decrease of systolic and diastolic blood pressure occurs without the clinical symptoms of hypotension. These data indicate that patients may be asymptomatic despite a drastic fall in systemic blood pressure.

The goals of the present study were to further evaluate the mechanisms responsible for the control of cerebral blood flow (CBF) in spinal cord injured patients by: (1) determining the autoregulation of $\mathrm{CBF}$ by measuring cerebral haemodynamics in patients with SCI and, (2) defining the differences between the patients with and those without the clinical manifestations of hypotension.

\section{Methods}

The investigation was divided into two parts. In the first part we studied the BP changes in 33 patients with SCI on a tilt table; 19 patients had complete and 13 patients had incomplete tetraplegia. Using Frankel's classification (Frankel et al., 1969) these incomplete patients were Frankel's B (3 patients), C (7 patients), and D ( 3 patients). All patients ( 7 female and 26 male) had paralysis at the C5-C7 spinal level and had suffered SCI injury 3 to 8 months prior to this study. Two patients were excluded from the study because of pre-existing arterial hypertension. Patients underwent simultaneous measurements of $\mathrm{BP}$ and heart rate $(\mathrm{HR})$ on a tilt table at $0,30,60$, and 80 degrees. All patients had volunteered and no patient was known to have any constitutional disease or complications which might have affected the results. Prior to the study patients fasted for at least 2 hours and rested for 15 to 20 minutes in a quiet air-conditioned room. Bladder catheterisation was performed 1 to 2 hours before the test. Some patients had slight to moderate spasticity, all patients spent the majority of their day in a wheelchair and no medication known to interfere with the control of blood pressure was used.

A motor driven tilt table (Activeaid Inc, Redwood Falls, MN) was used. Patients were monitored closely for symptoms of hypotension, and the test was discontinued if the patient experienced dizziness, nausea or blurred vision. Table I summarises the clinical data from the patients. In the group of 18 patients with complete

Table I Changes of blood pressure and heart rate in patients with spinal cord injury during tilting on tilt table

\begin{tabular}{|c|c|c|c|c|c|c|}
\hline \multirow[b]{2}{*}{ Group } & \multirow[b]{2}{*}{$\mathbf{N}$} & \multirow{2}{*}{$\begin{array}{c}\text { Hypotensive } \\
\text { symptoms }\end{array}$} & \multicolumn{2}{|c|}{ Blood pressure (mmHg) } & \multicolumn{2}{|c|}{ Heart rate (beats/min) } \\
\hline & & & Baseline & $\Delta \operatorname{Max}$ & Baseline. & $\Delta \operatorname{Max}$ \\
\hline $\begin{array}{l}\text { Complete tetraplegia } \\
\mathbf{n}=19 \\
\text { Incomplete tetraplegia } \\
\mathbf{n}=13\end{array}$ & $\begin{array}{l}26 \\
23 \\
16 \\
12\end{array}$ & $\begin{array}{l}(-) \\
(+) \\
(-) \\
(+)\end{array}$ & $\begin{array}{l}122 \pm 16 / 81 \pm 12^{8} \\
117 \pm 16 / 76 \pm 12 \\
123 \pm 16 / 79 \pm 11 \\
121 \pm 12 / 76 \pm 10\end{array}$ & $\begin{array}{l}-41 \pm 4 / 22 \pm 6 \\
-37 \pm 4 / 22 \pm 5 \\
-27 \pm 7 / 9 \pm 5 \\
-47 \pm 6^{\star} / 21 \pm 5^{\star \star}\end{array}$ & $\begin{array}{l}72 \pm 10 \\
71 \pm 10 \\
79 \pm 18 \\
76 \pm 13\end{array}$ & $\begin{array}{l}+24 \pm 10 \\
+14 \pm 7 \\
+16 \pm 4 \\
+14 \pm 7\end{array}$ \\
\hline
\end{tabular}

${ }^{8}$ Systolic/diastolic, mean $\pm \mathrm{SD} ; \mathbf{n}=$ number of patients; $\mathbf{N}=$ number of tests; Student t-test: ${ }^{\star} \mathrm{p}<0.01,{ }^{\star \star} \mathrm{p}<0.05$. 
tetraplegia 49 tests were done, in 13 patients with incomplete tetraplegia 28 tests were performed. The results were classified into two categories; asymptomatic and symptomatic, based on the presence of the clinical manifestation of hypotension (dizziness, nausea, or blurred vision) on the tilt table.

In the second part of the investigation, in addition to BP, HR and CBF were monitored. Nineteen patients were studied, 16 with tetraplegia (14-Frankel's A and 2-Frankel's B), and 3 patients with paraplegia (2-Frankel's A and 1-Frankel's B) above the T6 spinal segment level. All patients underwent testing on a tilt table as described above. During the tilting 10 patients were asymptomatic (asymptomatic group, Table II) and 9 had symptoms of $\mathrm{OH}$ (symptomatic group). Measurements were performed on the tilt table at $0,30,60$, and 80 degrees. BP, $\mathrm{HR}$ and CBF were measured simultaneously. CBF in the middle cerebral artery was determined bilaterally using a transcranial Doppler (Medasonic, Mountain View, CA) (DeWitt and Wechsler, 1988). BP and HR were determined with a digital instrument. CBF measurements were done on both middle cerebral arteries 10 times at each angle on the tilt table. The mean value of the measurements was used for statistical analysis. The co-efficient of variation among the measurements in individual tests was $8.7 \pm 1.5 \%$ (mean \pm SD). Statistical significance between the groups was determined using the Student t-test; the results of CBF in patients during tilting were analysed by the paired t-test.

\section{Results}

The results of the first part of the study are shown on Table I. Nineteen patients with complete tetraplegia were tested 49 times on tilt table. In 26 of these 49 tests the patients had no symptoms of $\mathrm{OH}$ and in 23 tests the patients had symptoms of $\mathrm{OH}$. Thirteen patients with incomplete tetraplegia were tested 28 times. In 16 tests the patients were asymptomatic while in 12 tests the patients had hypotensive

Table II Changes of blood pressure, heart rate and cerebral blood flow in patients with spinal cord injury during tilting on tilt table

\begin{tabular}{|c|c|c|}
\hline & \multicolumn{2}{|c|}{ Group of patients } \\
\hline & Asymptomatic & Symptomatic \\
\hline $\mathbf{n}$ & 10 & 9 \\
\hline Age & $30 \pm 17^{8}$ & $27 \pm 7$ \\
\hline Baseline BP (systolic/diastolic) & $110 \pm 16 / 70 \pm 7$ & $106 \pm 16 / 68 \pm 11$ \\
\hline$\Delta \max$ BP (systolic/diastolic) & $-23 \pm 10 / 10 \pm 7$ & $-29 \pm 13 / 11 \pm 6$ \\
\hline Baseline HR & $71 \pm 10$ & $73 \pm 10$ \\
\hline$\Delta \max H R$ & $+15 \pm 9$ & $+17 \pm 7$ \\
\hline $\mathrm{CBF}^{\star}(\mathrm{cm} / \mathrm{sec})$ at $0^{\circ}$ & $59 \cdot 2 \pm 9 \cdot 2$ & $58 \cdot 1 \pm 10 \cdot 8$ \\
\hline $30^{\circ}$ & $52 \cdot \overline{3} \pm 9 \cdot 1^{\mathrm{a}}$ & $51 \cdot 2 \pm 11 \cdot 2^{b}$ \\
\hline $60^{\circ}$ & $43 \cdot 7 \pm 8 \cdot 7^{a}$ & $40 \cdot 3 \pm 14^{a}$ \\
\hline $80^{\circ}$ & $40 \cdot 9 \pm 8^{a}$ & $32 \cdot 5 \pm 5^{a, c}$ \\
\hline $0^{\circ}$ & $59 \cdot 1 \pm 10 \cdot 6$ & $57 \cdot 9 \pm 11 \cdot 1$ \\
\hline
\end{tabular}

${ }^{\star} \mathrm{CBF}=$ cerebral blood flow, ${ }^{\&}$ mean $\pm \mathrm{SD} ; \mathrm{n}=$ number of patients; $\mathrm{a}=\mathrm{p}<0.001$; $\mathrm{b}=\mathrm{p}<0.01$ vs corresponding baseline value (paired t-test); $\mathrm{c}=\mathrm{p}<0.02$ by Student t-test symptomatic vs asymptomatic group 
symptoms. In both groups there was no significant difference in BP or HR in the horizontal position. During tilting on the table there was a progressive decrease in BP and an increase in the $\mathrm{HR}$ in both groups without significant differences between them. Only in the group of symptomatic patients with incomplete tetraplegia was there a significant decrease in the systolic and diastolic BP (47 \pm 6 and $21 \pm 5 \mathrm{~mm} \mathrm{Hg}$; systolic/diastolic) when compared to the decrease in the asymptomatic group (27 \pm 7 and $9 \pm 5 \mathrm{~mm} \mathrm{Hg}$; Table I).

Table II shows the results of BP and HR in the horizontal position ( 0 degrees) and the maximal change obtained during tilting in the group of patients studied for $\mathrm{CBF}$. In the asymptomatic group the mean baseline BP was $110 \pm 16 / 70 \pm 7 \mathrm{~mm}$ $\mathrm{Hg}$ (systolic/diastolic) which was not significantly different from the symptomatic group (106 $\pm 16 / 68 \pm 11 \mathrm{~mm} \mathrm{Hg}$ ). During tilting there was a non-significant difference in BP and HR between these two groups. In addition, the mean decrease in BP during tilting in the asymptomatic group $(23 \pm 10 / 10 \pm 7 \mathrm{~mm} \mathrm{Hg})$ was not significantly different when compared to the symptomatic group $(29 \pm 13 / 11 \pm 6$ $\mathrm{mm} \mathrm{Hg}$ ).

The changes in CBF velocity $(\mathrm{cm} / \mathrm{sec}$ ) in the middle cerebral artery as measured by the Doppler technique on the tilt table are shown in Table II. CBF velocity in both groups was significantly decreased during gradual elevation into the vertical

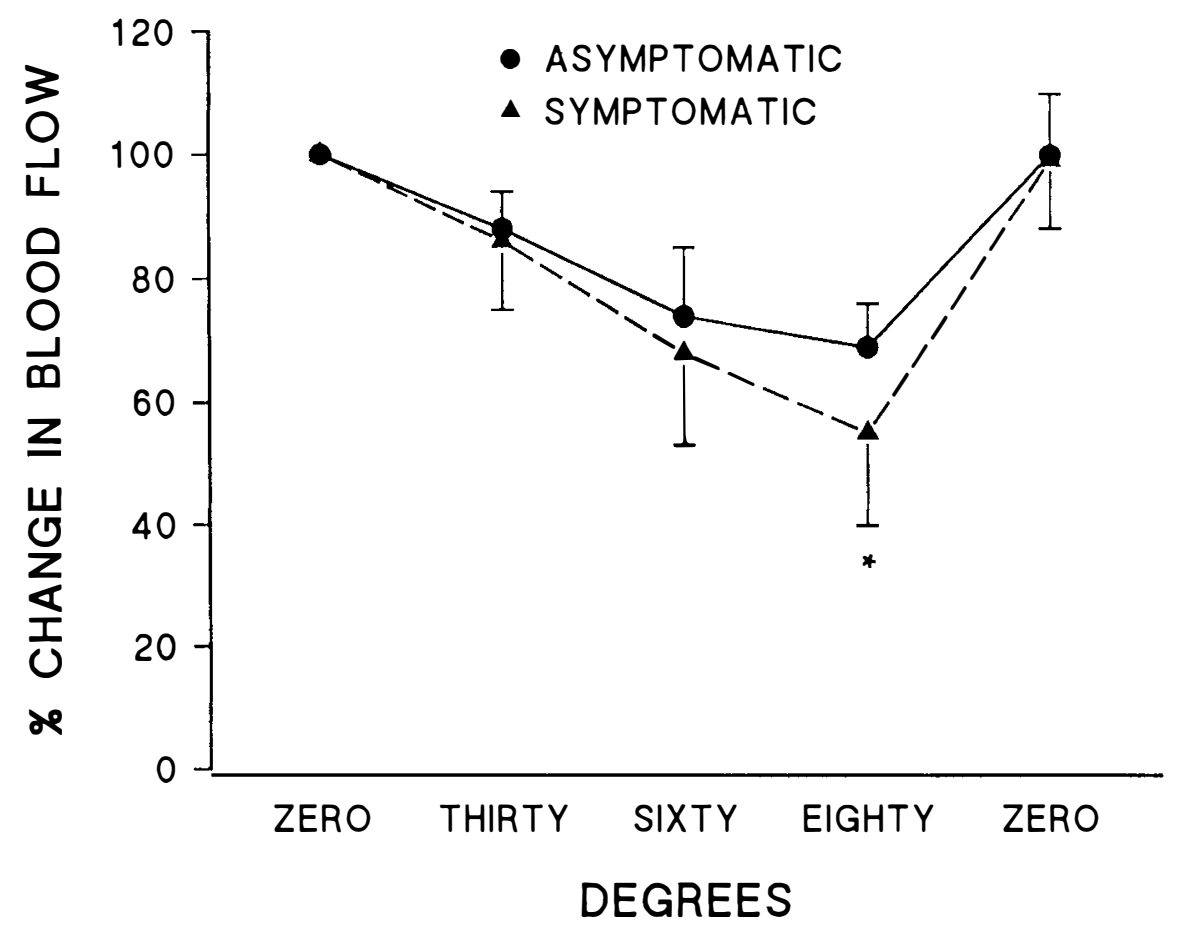

Figure Mean velocity of cerebral blood flow in the middle cerebral artery in tetraplegic patients during tilting expressed as percentage change from baseline. The abscissa indicates the angle on the tilt table. ( ) denotes asymptomatic and $(\boldsymbol{\Delta})$ symptomatic patients. The bars represent the standard deviation (shown only in one direction). The asterisks denotes statistical significance at the $p<0.001$ level. 
position even at the initial tilting to 30 degrees. The comparison of the symptomatic and asymptomatic groups showed that CBF velocity was only different at 80 degrees, which was the body position in which all but one patient in the symptomatic group experienced symptoms (Table II). This patient became symptomatic at 60 degrees. $\mathrm{CBF}$ in the symptomatic group during the hypotensive reaction on the tilt table at 80 degrees was $32.5 \pm 5 \mathrm{~cm} / \mathrm{sec}$ while in the asymptomatic group $\mathrm{CBF}$ was $40.9 \pm 8 \mathrm{~cm} / \mathrm{sec}(\mathrm{p}<0.02)$. A normalisation of CBF velocity was seen in both groups after resuming the horizontal position (Table II). The figure illustrates the per cent decrease in $\mathrm{CBF}$ in the asymptomatic and the symptomatic groups of patients. A significant difference in $\mathrm{CBF}$ was found at 80 degrees. In the symptomatic group the mean decrease in CBF from the baseline was to $55 \cdot 5 \pm 9 \cdot 6 \%$ and in the asymptomatic group it was to $69 \cdot 3 \pm 7 \cdot 2 \%$ ( $\mathrm{p}<0.001$ ). Eight of 9 patients in the symptomatic group had symptoms at CBF values lower than $30 \mathrm{~cm} / \mathrm{sec}$. In addition, all 9 patients developed symptoms of hypotension when the CBF velocity was reduced to $60 \%$ of the baseline value. Three paraplegic patients in the asymptomatic group had similar changes in BP, $\mathrm{HR}$, and CBF as those even in tetraplegic patients.

\section{Discussion}

$\mathrm{OH}$ is a common occurrence following SCI and in some tetraplegic patients this may significantly extend their rehabilitation period. The symptoms of hypotension are the result of the inadequate perfusion of the central nervous system (CNS) as a consequence of the sudden fall in BP caused by positional changes. The mechanisms important in the control of BP in patients with SCI have been reviewed by Lopes and Figoni 1981 and Figoni, 1984. It has been shown in spinal cord injured patients that cardiovascular, renal, neurological and endocrine systems are involved in the regulation of blood pressure. Different manoeuvres have been recommended for the therapy of $\mathrm{OH}$; however, the results are discouraging since they produce only limited improvement of symptoms. The use of elastic binders, corsets, inflatable pressure suits (Vallbona et al., 1963; McCluer, 1968), inhalation of $\mathrm{CO}_{2}$ (Downey et al., 1966), sympathomimetic drugs (Figoni, 1984), bladder percussion (Corbet et al., 1971b) or high salt diets (Claus-Walker and Halstead 1982) can only partially control the symptoms associated with $\mathrm{OH}$. The main goal of these procedures is to prevent the drop of the systemic BP induced by postural changes. Nanda et al. (1974) found that tetraplegic patients adapted to $\mathrm{OH}$, had an unchanged CBF despite a significant decrease in BP in the sitting position. They suggested that an autoregulatory mechanism maintained optimal CBF in spite of the fall in the systemic BP. Our data confirm these observations and also suggest that the tolerance to the symptoms of $\mathrm{OH}$ in patients with SCI results from the improved autoregulation of CBF. The adaptation to hypotension is a consequence of autoregulation, a phenomenon which may control blood supply in different organs and tissues (Johnson, 1984). We found a similar decrease of systemic BP in two groups of patients with SCI, but the symptoms of hypotension were present only in those patients exhibiting a more profound reduction in $\mathrm{CBF}$. It still remains to be determined what is the underlying mechanism(s) in the autoregulation of CBF flow. Experimental data suggest that acute autoregulation of $\mathrm{CBF}$ is controlled by different mechanisms from those 
controlling chronic autoregulation. It has not been determined to what degree myogenic, neurogenic, metabolic and other undefined factors are involved in the chronic autoregulation of blood supply in different tissues (Stainsby, 1973; Johnson, 1984).

It seems that the chronic adaptation to tissue hypoperfusion is associated with a proliferation of arterioles which may be an important compensatory process (Stainsby, 1973). Hogan and Hirschmann (1984) demonstrated that in ischaemic cremasteric muscle there was an increased number of arterioles. This was possibly, the result of stimulated angiogenesis by a substance secreted locally by macrophages and lymphocytes (Knighton et al., 1983). Since the adaptation of spinal cord injured patients with $\mathrm{OH}$ is a long term process (Spencer et al., 1969; Engel and Hildebrandt 1976), it is possible that angiogenesis in the CNS may have a role in the chronic autoregulation of blood supply.

In summary, our data suggest that systemic BP is not the predominant factor responsible for the symptoms of $\mathrm{OH}$. Cerebral autoregulation of blood flow seems to have a crucial function in these patients. Our data suggest that developing new therapeutic modalities aimed at improving the autoregulation of $\mathrm{CBF}$ may be more beneficial than solely focusing on increasing the systemic arterial pressure in SCI patients.

\section{Acknowledgement}

We thank Mr Bobby Butcher for technical assistance and Miss Carmen Borroto for typing the manuscript.

\section{References}

Claus-Walker J, Halstead LS 1982 Metabolic and endocrine changes in spinal cord injury: II Partial decentralization of the autonomic nervous system. Archives of Physical Medicine and Rehabilitation 63:576-601.

Corbet JL, Frankel HL, HaRris PJ 1971a Cardiovascular responses to tilting in tetraplegic man. Fournal of Physiology 215:411-431.

CoRbet JL, Frankel HL, HARRIS PJ 1971 b Cardiovascular changes associated with skeletal muscle spasm in tetraplegic man. Fournal of Physiology 215:395-409.

DEWITT DL, WECHSLER LR 1988 Transcranial doppler. Stroke 19:915-921.

Downey JA, CHIODi HP, MiLler JM 1966 The effect of inhalation of 5 per cent carbon dioxide in air on postural hypotension in quadriplegia. Archives of Physical Medicine and Rehabilitation 47: $422-426$.

ENGEl P, HildebrandT G 1976 Long term studies about orthostatic training after high spinal cord injury. Paraplegia 14:159-164.

FIGONI SF 1984 Cardiovascular and hemodynamic responses to tilting and to standing in tetraplegic patients: A Review. Paraplegia 22:99-109.

FRANKEL HL, HANCOCK DP, HYSLOP G et al. 1969 The value of postural reduction in the initial management of closed injury of the spine with paraplegia and tetraplegia. Paraplegia 7:179-192.

GutTMANN L, MUNRo AF, Robinson R, WALSH JJ 1963 Effect of tilting on the cardiovascular responses and plasma catecholamine levels in spinal man. Paraplegia 1:4-18.

Hogan RD, HiRSCHMANN L 1984 Arteriolar proliferation in the rat cremaster muscle as a long term autoregulatory response to reduced perfusion. Microvascular Research 27:290-296.

JOHNSON RH, PARK DM 1973 Effect of change of posture on blood pressure and plasma renin concentration in men with spinal transections. Clinical Science 44:539-546.

JohnSON RH, PARK DM, Frankel HL 1971 Orthostatic hypotension and the renin-angiotensin system in paraplegia. Paraplegia 9:146-152.

JoHNSON PC 1984 Autoregulation of blood flow. Circulation Research 59:483-495.

Kamelhar DL, Steele JM, Schacht RG, Lowenstein J, Naftehi NE 1978 Plasma renin and serum dopamine beta hydroxylase during orthostatic hypotension in quadriplegic man. Archives of Physical Medicine and Rehabilitation 59:212-216. 
Knighton DR, Hunt TK, Schenenstuhl H. Holliday BJ, Werb Z, Banda MJ 1983 Oxygen tension regulates the expression of angiogenesis factor by macrophages. Science 221:1283-1285.

LOPES P, FIGONI S 1981 Current literature on orthostatic hypotension and training in SCI patients. American Corrective Medical Therapy foumal 36:56-59.

MCCLUER S 1968 A temporary method of controlling orthostatic hypotension in quadriplegia. Archives of Physical Medicine and Rehabilitation 49:598-599.

NANDA RN, WyPER DJ, HARPER AM, JoHNSON RH 1974 Cerebral blood flow in paraplegia. Paraplegia 12:212-218.

SPENCER WA, Vallbona C, CARTER RE 1969 Physiologic concept of immunobilization. Archives of Physical Medicine and Rehabilitation 89-100.

SOMMERS DK 1979 Reactivity of the cardiovascular system in the tetraplegic patient. Clinical Pharmacology and Therapeutics 26:344-353.

StaINSBY WN 1973 Local control of regional blood flow. Annual Review of Physiology 35:151-168.

VAllbona C, SPENCER WA, CARduS D, DALE JW 1963 Control of orthostatic hypotension of quadriplegic patients with a pressure suit. Archives of Physical Medicine and Rehabilitation 44:7-18.

VALlBona C, LIPSCOMB HS, CARTER RE 1966 Endocrine responses to orthostatic hypotension in quadriplegia. Archives of Physical Medicine and Rehabilition 47:412-421. 